\title{
Bergson's Theory of Free Will
}

\section{Joel Dolbeault}

Journal of French and Francophone Philosophy - Revue de la philosophie française et de langue française, Vol XXVIII, No 2 (2020) pp 94-115

\author{
Vol XXVIII, No 2 (2020) \\ ISSN 1936-6280 (print) \\ ISSN 2155-1162 (online) \\ DOI 10.5195/jffp.2020.944 \\ www.jffp.org
}

\section{(cc) EY-NC-NO}

This work is licensed under a Creative Commons Attribution-Noncommercial-No Derivative Works 3.0 United States License.

\section{UILIS D-Surl}

This journal is operated by the University Library System of the University of Pittsburgh as part of its D-Scribe Digital Publishing Program, and is co-sponsored by the University of Pittsburgh Press 


\title{
Bergson's Theory of Free Will
}

\author{
Joel Dolbeault
}

University of Lille III

In short, contingency and freedom, it all means creation; freedom for us is creation.

—Henri Bergson, L'évolution du problème de la liberté,

Cours au Collège de France 1904-1905

The Bergsonian conception of free will is rarely discussed in the current debate. However, this conception is of real interest because Bergson develops an original form of indeterminism, capable of avoiding the main objection addressed to classical indeterminism: the objection of chance. For classical indeterminism, freedom of will implies a choice between several possible futures, traditionally called "alternative possibilities," and this point is targeted by the objection of chance. In contrast, for Bergson, freedom of will essentially implies inventing a future by forming an idea of action. It is not reduced to a choice between preset alternatives, and its dimension of invention, of creation, is enough to found indeterminism. The aim of this article is, therefore, to present the Bergsonian theory of free will and to show its relevance to the current debate.

Some recent publications have started to draw attention to the Bergsonian approach to free will. ${ }^{1}$ However, these analyses need to be further developed on several points: the criticism of alternative possibilities, the defense of an original form of agent causation, and the fact that Bergson discusses free will regardless of the question of moral responsibility. In addition, it is important to shed light on a crucial question related to the Bergsonian approach: the question of causation. While it is true that Bergson rejects the notion of mechanical causation to understand free will, he nevertheless uses a certain notion of causation. We must therefore clarify this concept and show that it does not imply determinism. 
Bergson developed his ideas on free will in his first book: Time and Free Will (1889). While most of what I will say relates to this book, Bergson brings some complementary elements to his theory throughout his work. In the first part of the article, I will explain how Bergson conceives of determinism and why he rejects this position. In the second part, I will explain how he conceives of classical indeterminism, based on the notion of alternative futures, and why he also rejects this position. Finally, in the third part, I will attempt to show that Bergson defends an original form of indeterminism based on a new approach to causation.

\section{The Criticism of Determinism}

\section{The Incompatibility between Free Will and Determinism}

In Time and Free Will, Bergson tackles the question of free will without starting from a precise definition of this notion, probably because starting from a precise definition would amount to presupposing too many things. ${ }^{2}$ However, he still presupposes two things: first, free will concerns the actions of a subject, of a self; ${ }^{3}$ secondly, there is an opposition between freedom and necessity. ${ }^{4}$

The first presupposition is shared by all philosophers who are interested in free will. However, in Bergson, this presupposition is reflected in his vocabulary: Bergson speaks much more often of "free act" than of "free will," 5 even if the question he addresses is essentially that of free will (in the words of the contemporary debate). This choice of vocabulary is not trivial. It can be explained by the idea that, as will is essentially turned towards action, it forms with action an overall process which must be considered as such. ${ }^{6}$

The second presupposition is frequently discussed. A lot of philosophers, indeed, reject the opposition between freedom and necessity. However, in Bergson, this second presupposition is ultimately a mere hypothesis, because the entire analysis he proposes consists in proving that a freedom opposed to necessity is conceivable, that is to say, to take up the challenge set by philosophers who reject this opposition. ${ }^{7}$ In other words, his approach is not at all to start from a clear, conceptual opposition between freedom and necessity, and then to deduce various propositions. His approach instead is to start from an intuitive opposition between freedom and necessity, then to show that this intuitive opposition can be translated into a clear conceptual opposition.

The hypothesis of an opposition between freedom and necessity corresponds to the hypothesis of an incompatibility between freedom and determinism. In the terms of contemporary debates, this is therefore an incompatibilist hypothesis. However, to fully understand this hypothesis, it is important to understand how Bergson characterizes determinism. 
Bergson distinguishes two kinds of determinism: physical determinism and psychological determinism. Physical determinism is the idea that all physical phenomena are governed by laws. ${ }^{8}$ This determinism concerns the question of free will provided that we add a hypothesis that reduces psychic life to cerebral life. ${ }^{9}$ Psychological determinism is formed on the model of physical determinism. It conceives of the self as a set of distinct states whose evolution is governed by laws. ${ }^{10}$ For the two determinisms, the notion of law is therefore central because laws are conceived as the foundation of necessity. From this point of view, determinism says something more than the principle of universal causation (PUC):

The PUC:

Every phenomenon is determined by a cause.

Determinism:

Every phenomenon is determined by a cause whose action obeys laws.

Consequently:

Every phenomenon is determined by a cause before it even occurs.

From the point of view of the PUC, a phenomenon may have a cause whose action does not obey laws. In the third part of the article, we will see that Bergson characterizes the free act in this way. In contrast, from the point of view of determinism, every phenomenon is determined by a cause whose action obeys laws. This implies that any phenomenon is determined before it occurs. ${ }^{11}$ In other words, the characteristics of a phenomenon are fully fixed before the phenomenon occurs. From this point of view, every phenomenon has a kind of virtual existence in its cause before having an actual existence, and causation is only the actualization of this virtual reality.

That said, Bergson's incompatibilist hypothesis consists in thinking that the concept of free will corresponds to the fact of creating the future, as opposed to the fact of actualizing an already fixed future. This appears in particular in the passage where he compares the free act to artistic creation:In short, we are free when our acts spring from our whole personality, when they express it, when they have that indefinable resemblance to it which one sometimes finds between the artist and his work. ${ }^{12}$ According to this hypothesis, the free act is like artistic creation: it does not achieve a perfectly predefined plan, nor does it actualize a future mechanically predetermined by physical or psychological laws. It produces something that does not virtually preexist.

In the books that follow Time and Free Will, Bergson repeatedly emphasizes this creative character of free will. ${ }^{13}$ Moreover, in his lectures at the Collège de France on freedom (1904-1905), one passage is particularly clear on this point: 
I summarize what I have just said: in short, contingency and freedom, it all means creation; freedom for us is creation. . . . We have already made this comparison, but we will come back to it often; freedom is a creation in the sense that one takes this word when one says that there is creation in a work of art. What do we mean by this? We do not mean that the work of art is an ex nihilo production, that it comes from nothing; by this we mean that, given the conditions which contributed to the production of the work, the work, if it is truly the work of an artist, adds to these conditions something absolutely new, absolutely unforeseeable. ${ }^{14}$

\section{Arguments against Determinism}

In Time and Free Will, Bergson puts forward several reasons for rejecting determinism in order to justify his incompatibilist hypothesis. First, he asserts that free will understood as a creation is given to consciousness as a fact; second, in response to physical determinism, he argues that there is no evidence that psychic life is reduced to cerebral life; third, in response to psychological determinism, he argues that the singularity of our deep-seated psychic states implies that they cannot be governed by laws.

For Bergson, free will is given to our consciousness as a fact: "Freedom is therefore a fact, and among the facts which we observe there is none clearer." ${ }^{15}$ In connection with the two presuppositions mentioned above, this fact presents two aspects: on the one hand, it appears that, at certain moments, our future depends on the plan of action which we form on the basis of our values; ${ }^{16}$ on the other hand, it appears that our future is only imperfectly prefigured by this plan because the latter depends on a self which is constantly evolving, and which can therefore be modified as long as the action is not completed. ${ }^{17}$ In this sense, the immediate intuition of our freedom is nothing other than the immediate intuition of our own duration in the realm of action.

Despite this appearance, free will might be an illusion. However, from a methodological point of view, what is given to consciousness as a fact must be taken for real until it is shown to be an illusion. This is where the discussion with determinism comes into play. According to determinism, at any time, the psychic state of the self depends on what precedes and on the laws of nature. This amounts to saying that, at any time, our psychic state is determined (fixed) before it occurs.

For physical determinism, the determination in advance of our psychic states would be explained by the reduction of psychic life to cerebral life (the latter being conceived as governed by laws). In Time and Free Will, Bergson raises three objections to this hypothesis. First, the strict parallelism 
(isomorphy) between psychic life and cerebral life is not proven. Certainly, any state of mind gives rise to a brain state. But that is not enough to prove parallelism because one can always imagine that several different psychic states give rise to the same cerebral state. Since psycho-physical parallelism has not been proved, neither has the reduction of the psychic activity to the cerebral one. ${ }^{18}$ The second element is that the law of conservation of energy does not allow us to prove this reduction because it has not been proved that this law applies to all physiological phenomena, in particular to cerebral phenomena. ${ }^{19}$ The third element is that the law of conservation of energy only applies to systems which, in absolute terms, are likely to return to one of their previous states. Now, it seems impossible that a being with a conscious life can go through the same state twice. In such a being, in fact, the past accumulates in memory and mixes with the present, thus making each present moment something new. ${ }^{20}$ We understand by this that physical determinism presupposes a conception of psychic life which neglects the action of duration. In this sense, it presupposes psychological determinism. ${ }^{21}$

After Time and Free Will, Bergson develops the first two elements. In Matter and Memory, he attempts to show that there is no strict parallelism between pure memory (what we call today "episodic memory") and the brain. $^{22}$ In Creative Evolution and later Mind-Energy, he explains that the creation of a tiny amount of energy by a living being can have significant physical effects. To accomplish this aim, this energy has to be used to trigger a mechanism using a large amount of energy first extracted from the environment. ${ }^{23}$

For psychological determinism, the determination in advance of our psychic states would be explained by psychological laws. Against this idea, Bergson presents an argument based on the continuity of psychological life. This argument can be summarized as follows:

(i) Our deep-seated psychic states bear the mark of the time that has elapsed: they are formed by the whole of our memory.

(ii) Therefore, our deep-seated psychic states are singular.

(iii) However, a law can only govern instances of universals.

(iv) Consequently, the evolution of our deep-seated states is not governed by laws. ${ }^{24}$

Our deep-seated psychic states are our most intimate feelings, thoughts and aspirations. ${ }^{25}$ They make our personality and tend to direct our life, that is to say to determine our will at certain crucial moments. According to Bergson, these deep-seated psychic states are formed by the whole of our memory in the sense that they are the synthesis of all of our past experiences. For example, the feeling of love that we may have for a person at a given time 
is formed by all of our past history with that person and, more generally, by all of our past relationships with other people.

Point (ii) is the consequence of point (i). As our past experiences are singular, ${ }^{26}$ the deep-seated psychic states formed from them are also singular. Furthermore, as our past experiences accumulate over time, our deep-seated psychic states are constantly evolving, if only imperceptibly. In other words, these states are never repeated over time.

Point (iii) introduces an indisputable idea: a law is a certain relation between universals; therefore, it can only govern instances of universals. To better understand this, one can make a comparison with physics. If some laws seem to govern physical processes, it is because these systems seem to be reduced to a set of typical qualities (mass, electric charge, position, speed, and so forth) which differ only in quantity. In the field of psychology, the situation looks different.

Point (iv) is the logical consequence of points (ii) and (iii). If our deepseated psychic states are singular, their evolution cannot be governed by laws.

According to Bergson, the mistake of psychological determinism is that it is based on an associationist view of the mind. Basically, associationism conceives of the mind as a set of tendencies without singularity, governed by laws of force. ${ }^{27}$ In so doing, psychological determinism is deceived by the language which designates our tendencies by general and impersonal terms: "love," "hate," and so forth. In reality, due to the continuity of psychological life, "each of us has his own way of loving and hating; and this love or this hatred reflects his whole personality."28

\section{The Criticism of Classical Indeterminism}

\section{The Paradox of Free Will in Classical Indeterminism}

Bergson rejects determinism, but he also rejects a certain form of indeterminism. As this form generally corresponds to the position of those who defend indeterminism, ${ }^{29}$ I will speak of it as classical indeterminism.

Classical indeterminism considers that the following fact is given to consciousness: "when we perform an action freely, some other action would have been 'equally possible.'" ${ }^{30}$ Moreover, in classical indeterminism this fact is understood as follows: imagine that at some moment $\mathrm{O}$, I decide to perform an act $X$; this decision is free if and only if, at this same moment $\mathrm{O}$, and without any modification of the world or of myself, I can decide to perform an act $Y$ (different from $\mathrm{X}$ ). ${ }^{31}$ Therefore, from this point of view, a free decision does not entirely depend on what precedes it. ${ }^{32}$

Bergson explains classical indeterminism using a diagram. This diagram represents a self which traverses a series of psychic states $\mathrm{MO}$, then finds itself before two future directions OX and OY, equally open, as in the figure below. 
The fact that $\mathrm{OX}$ and $\mathrm{OY}$ are two equally open directions implies that the choice made at point $\mathrm{O}$ does not totally depend on what precedes it.

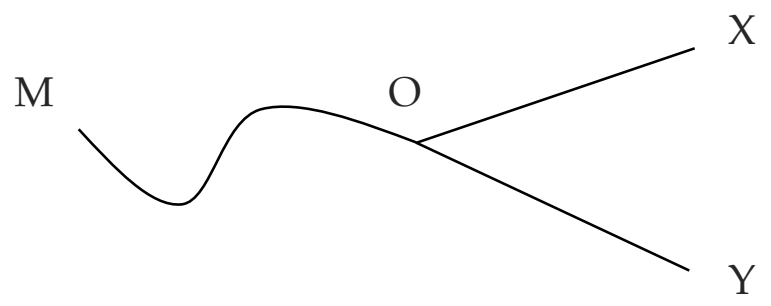

Fig. 1 Schematic representation of the free act for classical indeterminism (Bergson, Time and Free Will, 176).

Bergson presents this form of indeterminism without referring to any specific philosopher defending this view. ${ }^{33}$ However, it is likely that he is thinking of Descartes. Two elements justify this interpretation. First, this form of indeterminism corresponds fairly well with Descartes's position, whose central point is that our will is totally independent of our passions and knowledge - a total independence which allows us to make a decision against our passions and/or our reason. ${ }^{34}$ Secondly, in his lectures at the Collège de France on freedom, Bergson underlines the fact that Descartes defends a form of indeterminism the consequence of which is to make the human will similar to the divine will: as radically independent from all determination. ${ }^{35}$

Bergson may also be thinking of Kant who also defends the central idea of classical indeterminism: an action is freely performed if the agent can also choose not to perform this action. ${ }^{36}$ For Kant, as for Descartes, a free action is radically independent from all determination. What is original in Kant is that free action emanates from a will clearly conceived as intelligible, that is, outside of space and time. ${ }^{37}$

Finally, it should be noted that classical indeterminism is the most frequently defended form of indeterminism today in philosophy. For contemporary indeterminist thinkers, indeed, free will implies a choice between alternative futures, called "alternative possibilities," and in some authors we find a diagram very similar to the one made by Bergson. ${ }^{38}$ Moreover, free will implies a choice independent of any determination. In this sense, these thinkers assert that an agent can make a decision without any 
rational preference ${ }^{39}$ or against her rational preference. ${ }^{40}$ From this point of view, the choice between alternatives is not determined by a reason (nor by anything else), even if each alternative has its own reasons.

In contrast with determinism, classical indeterminism asserts that, at certain times, several futures are possible for an agent. However, according to Bergson, this indeterminism yields several paradoxes. A first paradox concerns the free act: if the free act implies a choice independent of all determination, it implies a kind of indifference ${ }^{41}$ - the most striking manifestation of this indifference being the capacity to choose against one's rational preference. A second paradox concerns the self: if the free act comes from the self, and if it implies a choice independent of all determination, then the self itself must be conceived as independent of all determination, that is to say without any quality. ${ }^{42}$

As such, this conception is not incompatible with the two elements presupposed by Bergson: first, free will concerns the actions of a self; secondly, there is an opposition between freedom and necessity. However, it leads us to conceive of the free act and the self in a counterintuitive way.

\section{Arguments against Classical Indeterminism}

Bergson rejects classical indeterminism for two reasons. The first reason is that it develops a conception of the free act which does not correspond with experience.

Classical indeterminism asserts that alternative possibilities are a fact given to consciousness. ${ }^{43}$ However, for Bergson, this fact is illusory. What is given to consciousness is not the ability to choose between already defined ideas of action, corresponding to already fixed futures, ${ }^{44}$ but the ability to invent ideas of action and to change our mind, even when we have already made a decision. ${ }^{45}$ In other words, what is given to consciousness is not the ability to choose between already fixed futures, but the ability to invent our own future.

The experience of free will according to classical indeterminism:

At certain times, I choose between several possible futures (already fixed).

The experience of free will according to Bergson:

At certain times, I invent my future by forming an idea of action.

Bergson adds that an illusion can explain why so many philosophers conceive of free will as implying alternative possibilities. The starting point is that our intelligence ${ }^{46}$ finds it difficult to conceive of the process of forming a will because this process relates to something that is always changing: ideas of action that appear, that gradually become more precise, that change more or less, etc. As a result, we spontaneously create a simplified and symbolic representation of this process, as if it related to something fixed: two or three 
ideas immediately and completely defined between which the self would oscillate. In doing so, we do not take into account the inventive effort of the self and equate reflection with a mechanical oscillation. Furthermore, since we consider ideas as immediately and completely defined, we assimilate these ideas to virtual future actions waiting for an actualization, such as actions $\mathrm{X}$ and $\mathrm{Y}$ in the figure above. ${ }^{47}$ In this way, we fix and spatialize psychological duration. ${ }^{48}$ For Bergson, this diagram is therefore not trivial: consciously or unconsciously, it corresponds to the way in which our intellect symbolizes the process of forming a will through a spatial image. ${ }^{49}$ The problem is that this image is misleading for philosophy because it tends to mask the inventive capacity of the self, that is to say the essence of freedom.

The second reason to reject classical indeterminism is that it develops a conception of the self which does not correspond with experience. In classical indeterminism, the self must be independent of all determination. It can therefore be conceived of in two ways: either as an invariable reality in time (that is to say as a permanent substrate of the successive psychic states); or, more radically, as a reality out of time. The first version corresponds to the Cartesian self; the second version to the Kantian self as a thing-in-itself. However, neither the self as an invariable reality, nor the self as a reality out of time is given in experience. What is given in experience is a constantly changing self, both in life in general and during the process of forming a will. $^{50}$

Some may respond that the concept of the self as an invariable reality is justified in another way, when it comes to accounting for the unity of the self through time. In this case, the invariable self can be thought of as what allows the successive psychic states to be linked. However, according to Bergson, this concept is based on an error which consists in conceiving of psychological life as discontinuous, that is, as a succession of distinct states. ${ }^{51}$ In reality, each present psychic state is more or less penetrated by memories, and the unity of the self through time corresponds to the permanent penetration of its past into its present.

Another difficulty concerns the relation of this undetermined self to its reasons: on the one hand, indeterminist philosophers acknowledge that reasons do play a role in free decision; on the other hand, they claim that free decision is independent of all determination. But it is difficult to understand how to reconcile these two assertions. ${ }^{52}$

Finally, for Bergson, classical indeterminism differs little from determinism in the way it represents psychological life. Both neglect psychological duration, that is, psychological continuity. Likewise, both have a purely symbolic view of the process of forming a will, which relates to fixed ideas of action that are comparable to spatial directions. ${ }^{53}$ Consequently, both neglect the creative nature of freedom: 
That is why, in spite of all their efforts, [most philosophers] cannot succeed in conceiving the radically new and unforeseeable. I speak not only of those philosophers who believe in so rigorous a concatenation of phenomena and events that effects must be deduced from causes: such philosophers imagine that the future is given in the present, that it is theoretically visible in it, that to the present it will add nothing new. But even those few who have believed in free will, have reduced it to a simple "choice" between two or more alternatives, as if these alternatives were "possibles" outlined beforehand, and as if the will was limited to "bringing about" ("realiser") one of them. They therefore still admit even if they do not realize it, that everything is given. They seem to have no idea whatever of an act which might be entirely new (at least inwardly) and which in no way would exist, not even in the form of the purely possible, prior to its realization. But this is the very nature of a free act. $^{54}$

The only difference between the two positions is that classical indeterminism invokes a self without determination, able to choose any of these directions, whereas determinism does not invoke this self and concludes that, in each situation, only one direction is really possible. However, classical indeterminism seems much less robust than determinism. ${ }^{55}$

\section{An Original Form of Indeterminism}

\section{The Free Act}

As I said at the outset of the article, Bergson presupposes two things: first, free will concerns the actions of a self; second, there is an opposition between freedom and necessity. Classical indeterminism seeks to reconcile these two points by asserting that the free act emanates from a self who is independent of all determination. The problem is that this self does not correspond with any experience. The solution proposed by Bergson is quite different. It consists in affirming that the free act emanates from "the whole of the self," 56 "the whole soul," 57 "our whole personality," 58 and that the self as a whole (i.e., with all its determinations) is singular. This singularity, indeed, ensures that its activity cannot be governed by laws.

More precisely, the free act always emanates from a state of the self which reflects the whole of the self, ${ }^{59}$ due to the penetration of our memory in this state. In this sense, Bergson writes that some of our states agree "with the whole of our most intimate feelings, thoughts and aspirations, with that particular conception of life which is the equivalent of all our past experience." ${ }^{\prime 60}$ In terms of the contemporary debate, we can see that, for Bergson, the free act requires an event causation which is also an agent 
causation. On the one hand, every act (free or not) emanates from a certain state of the self, and therefore requires an event causation. But on the other hand, the free act emanates from a specific state of the self: a state which reflects the whole of the self. Therefore, it also requires an agent causation. In this sense, the free act combines the two causations, which are not opposed. In contemporary libertarianism, their opposition comes from the failure to take into account the psychological continuity which allows an agent to be entirely in one of its states. ${ }^{61}$

Insofar as the free act comes from the self as a whole, we can see that freedom is not to be sought in indifference. ${ }^{62}$ On the contrary, it is to be sought in the maximum commitment of the self in a state. From this point of view, Bergson anticipates the so-called objections to human freedom based on Libet type experiences. Basically, since these experiences relate to indifferent acts (probably in reference to classical indeterminism), they do not relate to freedom at all. ${ }^{63}$

Insofar as the free act comes from the self as a whole, we can also see that freedom admits of degrees. ${ }^{64}$ These degrees correspond to the fact that the self can be more or less engaged in each of its states. The lowest degree corresponds to acts performed almost automatically because these acts depend on a small part of our mind that has become independent from the whole. Let us think in particular of acts performed out of habit, ${ }^{65}$ or certain impulsive acts. ${ }^{66}$ The highest degree corresponds to the acts which depend on the whole of our mind, that is to say, which express our global conception of life. ${ }^{67}$ And between the two, there are acts which depend on a set of ideas and feelings that are more or less well merged with the rest of our mind, for example, certain ideas inherited from our education but more or less consistent with the rest of our ideas. ${ }^{68}$

\section{Does Bergson Define the Free Act?}

On the one hand, Bergson proposes several formulae which look like definitions of the free act:

It is the whole soul, in fact, which gives rise to the free decision: and the act will be so much the freer the more dynamic series with which it is connected tends to be the fundamental self. ${ }^{69}$

In short, we are free when our acts spring from our whole personality. ${ }^{70}$

But on the other hand, he asserts that freedom is not definable, and that any attempt to define it will ensure the victory of determinism. ${ }^{71}$ How should we understand this? 
In fact, the question is twofold. First, are the formulae proposed by Bergson definitions of the free act? Secondly, can these formulae actually work in favor of determinism?

The answer to the first question depends on what is meant by the word "define." If defining an object consists in characterizing this object in general, then the formulae proposed by Bergson are indeed definitions of the free act. However, in Time and Free Will, Bergson gives a limited meaning to the word "define." For him, defining an object consists in analyzing this object, ${ }^{72}$ that is to say in reducing it to elements that are already known. ${ }^{73}$ From this point of view, the formulae proposed by Bergson are not definitions of the free act because they seek to say what the free act is without employing the already known notions of everyday or philosophical language. In these formulae, Bergson introduces a series of new expressions aimed at designating the self while taking into account psychological continuity: "the whole of the self," "the whole soul," "our whole personality." Moreover, these formulae evoke the idea of causation but without using the terms "cause" or "causation," probably because too many misleading meanings are attached to these terms in the philosophical tradition. This is why Bergson uses metaphorical expressions: the whole soul "gives rise" to the free decision; ${ }^{74}$ free acts "spring" from our whole personality ${ }^{.75}$

The answer to the second question is that, for Bergson, only the analytic definitions of the free act ensure the victory of determinism. This explains why Bergson essentially criticizes these definitions, not his own formulae. Three definitions are targeted in particular, which are based respectively on the concepts of possibility, forecasting, and necessity. ${ }^{76}$ These three definitions evoke a mysterious contingency which it is difficult not to assimilate with chance. We understand then that they can work in favor of determinism.

In the terminology of The Creative Mind, ${ }^{77}$ the analytic definitions of the free act use notions already stored in our language to obtain an immediate clarity. However, as these notions are somewhat confusing, the question of free will is ultimately obscured. In contrast, the intuitive definitions proposed by Bergson are based on new notions, closer to the real data of consciousness. These notions may seem obscure at first sight, but their use aims to provide a new clarity concerning the question of free will.

\section{Free Will and Causation}

We have shown that the formulae proposed by Bergson to characterize the free act evoke the idea of causation, but without using this term. This can be explained by the fact that Bergson seeks to renew the notion of causation.

In classical indeterminism, the rejection of determinism rests on the assumption that the self can be a cause acting independently of any determination. The problem is that the action of such a cause seems 
indistinguishable from the action of chance: like the action of chance, under strictly identical conditions, this action can produce various effects, without any explanation. In this sense, a recurring criticism against classical indeterminism in contemporary debate is that it introduces an element of chance into free will. ${ }^{78}$ This element amounts to a rejection of the PUC.

In contrast, in the indeterminism defended by Bergson, the rejection of determinism rests on the assumption that the self is singular. Such an assumption does not threaten the PUC in any way. However, it leads us to question the nature of causation. From this point of view, the third chapter of Time and Free Will, dedicated to free will, can be read as aiming to show that psychological causation is something other than mechanical causation.

Certain passages of the book seem to contrast freedom and causation. Thus, at the beginning of chapter 3, Bergson evokes a will "capable of willing for willing's sake,"79 as if this will could want without reason. He also mentions "effects which precede their causes," 80 as if free action could be an effect without cause. Some commentators have thus attempted to present Bergson's position without using the notion of causation, ${ }^{81}$ or by bringing Bergson closer to classical indeterminism. ${ }^{82}$ However, in other passages, Bergson clearly states the need to develop a new conception of causation, opposed to determinism: ${ }^{83}$

The determinist, however, led astray by a conception of duration and causality which we shall criticize a littler later, holds that the determination of conscious states by one another is absolute. ${ }^{84}$

We shall not insist for the moment on this last point: we reserve the question in what sense the ego perceives itself as a determining cause. ${ }^{85}$

Moreover, at the end of chapter 3, Bergson devotes a long analysis to the notion of causation to show that this notion is not opposed to that of freedom. ${ }^{86}$ According to him, all causation is basically the prefiguring of one phenomenon by another. But there are two kinds of prefiguring: the perfect prefiguring, thought on the model of mathematics, and the imperfect prefiguring, thought on the model of psychic life. According to the first model, an effect is prefigured in its cause as a theorem is prefigured in the definition of a geometric figure. ${ }^{87}$ Causation then resembles a deduction. It requires laws: given a type $A$ state and a law "if $A$, then $B$," then a type B state will necessarily occur. We can also say that, in this model, causation is only the actualization of a virtual reality: here, the actualization of the type B state whose virtual existence is based on the type A state and the law "if A, then B." In contrast, according to the second model, an effect is prefigured in its cause as an action is prefigured in an idea. ${ }^{88}$ From this point of view, causation is not analogous to deduction. It appears as an effort to move from an idea to an action. This effort implies a progressive specification of the idea. ${ }^{89}$ For 
example, if the idea is to go out for a walk, the effort consists in thinking of a series of actions (getting up, switching off certain electrical devices, taking a piece of clothing, etc.), then in using the sensorimotor representations making it possible to accomplish these actions. In more complex cases, which concern the question of free will, the initial idea is simply to answer a problem, and the effort consists in creating various ideas of action which we can compare, modify, and specify to have an action plan. So, in this model, causation has a creative dimension. It is no longer the actualization of a virtual reality, but the progressive formation of a new reality. In the terms of Mind-Energy, it is a "gradual passage from the less realized to the more realized, from the intensive to the extensive." 90

According to Bergson, when it comes to understanding psychological life, the first model of causation is not necessary. There are three reasons for this:

The first reason is that causation as creation seems to be given in experience. It is precisely the experience of freedom:

On the one hand, we know force only through the witness of consciousness, and consciousness does not assert, does not even understand, the absolute determination, now, of actions that are still to come: that is all that experience teaches us, and if we hold by experience we should say that we feel ourselves free, that we perceive force, rightly or wrongly, as a free spontaneity. ${ }^{91}$

The second reason is that the continuity of psychological life makes that the deep-seated psychic states are singular. It is therefore difficult to understand how their evolution could be governed by laws (see above).

The third reason is that the mathematical model of causation is not a priori better than the psychological model. Admittedly, the mathematical model immediately meets the requirements of our intelligence which naturally tends to apprehend things in a geometric manner. ${ }^{92}$ However, this does not prove that this model can be applied to everything, in this case to psychological life. In addition, this model presents an intrinsic difficulty: since causation implies time, an effect is never really deduced from its cause. In other words, an effect is never logically necessary. It is, at best, metaphysically necessary. ${ }^{93}$ In this sense, the hypothesis of laws which would govern all or part of the processes is a metaphysical hypothesis, even if it is largely inspired by science. Basically, this hypothesis is a Platonism adapted to modern science: for Plato, there are universals (Ideas) which have a formative action on the physical world by being the condition of possibility of physical things and beings; in the hypothesis of laws, there are relations between universals (laws) which have a formative action on the physical world by governing the evolution of processes. ${ }^{94}$ According to Bergson, this Platonism as a global view of nature can be questioned. ${ }^{95}$ 


\section{Free Will and Rationality}

The originality of the Bergsonian theory of free will can also be seen with regard to the relation between free will and rationality.

For classical indeterminism, free decision comes from a self independent of its determinations. Therefore, this decision can be made without rational preference or against a rational preference-a position that we find today in contemporary indeterminism. ${ }^{96}$ In contrast, for Bergson, any free decision is rational. However, it is important to distinguish between two types of reason.

On the one hand, Bergson rejects the idea that free decision is the result of a set of reasons quite distinct and easily expressible in everyday language. This would indeed amount to conceiving of psychological life in a mechanistic way, that is to say to adopt the view of psychological determinism. ${ }^{97}$ On the other hand, Bergson asserts that free decision is based on "our personal idea of happiness and honor," which is "the best of reasons." ${ }^{98}$ In other words, he asserts that the self, as a synthesis of ideas and feelings, plays as a unique reason in a free decision. From this point of view, there is no ambiguity, Bergson combines free will and rationality. After Time and Free Will, he emphasizes this point again: "But, in man, the thinking being, the free act may be termed a synthesis of feelings and ideas and the evolution which leads to it a reasonable evolution." 99

Now, given that the reason for a free decision is singular, an agent may be unable to explain this reason to others, or even to itself. Consequently, its decision may seem irrational. ${ }^{100}$ This explains the surprising passages that were mentioned above. When Bergson evokes a will "capable of willing for willing's sake," ${ }^{101}$ he in fact evokes a will incapable of analyzing its own reason, that is to say, of reducing this reason to common and impersonal elements. Besides, in this same passage, he suggests that this will rests on a hidden, but "decisive reason." ${ }^{102}$ Likewise, when Bergson refers to some "effects which precede their causes," ${ }^{103}$ he is simply alluding to the fact that a free decision may occur before the agent finds an analytical expression of the reason for its decision.

\section{Free Will and Moral Responsibility}

In contemporary discussions, thinking about free will goes hand in hand with thinking about moral responsibility, as if these two notions were intimately linked. In trying to understand this connection, we first find the idea that moral responsibility is a sort of moral quality of agents which makes that the latter may deserve praise or blame for their actions. We also find the idea that moral responsibility would imply free will, because it appears as illegitimate to praise or blame an agent who would have acted without freedom. We finally find the idea that, because of this implication, moral 
responsibility could help to understand free will: where there is moral responsibility, there would be free will.

The Bergsonian approach to free will is very different: this approach completely ignores the notion of moral responsibility. There are two reasons for this. First, according to Bergson, the fundamental basis for understanding free will is the sui generis experience of free will, and not a notion belonging to our common or philosophical language (which may be misleading). Second, because of this experience, the question of free will appears to be a metaphysical question with no specific relation to the concept of moral responsibility. For Bergson, the question of free will is this: am I the creator of my future, or is this future already determined? It is not at all obvious that the notion of moral responsibility can shed light on this question. Moreover, in contemporary discussions, there are several conceptions of moral responsibility, some compatible with determinism, others not. Therefore, this notion is more likely to obscure the question of free will than to clarify it.

Another problem arises. In contemporary discussions on free will, moral responsibility is often thought without regard for any usefulness. ${ }^{104}$ However, being accountable to someone, and deserving of praise or blame, intuitively seems to have a purpose: to encourage agents to behave according to certain rules. Therefore, moral responsibility appears as something aimed at exerting a certain pressure on agents. The problem is that, for Bergson, free decision comes from ourselves, not from outside pressure. In Bergsonian terms, this decision emanates from the fundamental self, not from the social self. ${ }^{105}$ Therefore, there seems to be a tension between moral responsibility and free will, in the sense that the former can threaten the latter.

Does this mean that Bergson conceives of human life without moral responsibility? The answer is negative because we are also social beings who have duties towards others. However, this point does not remove the tension between moral responsibility and free will.

Does this mean that, for Bergson, free will is on the side of selfishness? There too, the answer is negative because, for him, human beings have a natural capacity for love, which may wake up in contact with exceptional moral personalities. ${ }^{106}$ In this case, it is the fundamental self that is moral, that is, the self from which the free acts emanate.

\section{Conclusion}

Bergson defends an original form of indeterminism: an indeterminism without the notion of alternative possibilities. The basis of this originality is a certain conception of causation: in the free act, causation must not be conceived as the actualization of a pre-fixed virtual reality, but as the progressive formation of a reality which is not pre-fixed. Thanks to this conception, Bergson can reject determinism without rejecting the principle of 
universal causation. The indeterminism he defends therefore escapes the objection of chance, which is a recurring objection against indeterminism in the contemporary debate.

After Time and Free Will, Bergson deepens and widens his research on free will. In Matter and Memory, he develops an additional argument against physical determinism, seeking to prove the independence of pure memory from the brain. In Creative Evolution, he seeks to show that the living world as a whole is creative, and that human freedom is not an anomaly in nature.

1 See, in particular, Mark Robson, "Is Ultimate Moral Responsibility Metaphysical Impossible? A Bergsonian Critique of Galen Strawson's Argument," Philosophy 92, no. 4 (2017): 519-538; Mark Sinclair, Bergson (London: Routledge, 2020), ch. 3.

2 Henri Bergson, L'évolution du problème de la liberté. Cours au Collège de France 1904-1905 (Paris: Presses Universitaires de France, 2017), 17.

${ }^{3}$ Henri Bergson, Time and Free Will, trans. F. L. Pogson (New York: Dover, 2001), 142-143.

${ }^{4}$ Ibid.

${ }^{5}$ Bergson, Time and Free Will, ch. 3.

${ }^{6}$ See, in particular, Bergson, L'évolution du problème de la liberté, 18.

${ }^{7}$ For this challenge, see David Hume, An Enquiry Concerning Human Understanding and Other Writings (Cambridge: Cambridge University Press, 2007), 72.

${ }^{8}$ Bergson, Time and Free Will, 143.

${ }^{9}$ Bergson, Time and Free Will, 143-144.

${ }^{10}$ Bergson, Time and Free Will, 158-159, 199.

11 The idea is as follows: given certain laws, any type A state will necessarily evolve to a type $B$ state, then $C$, then $D$, and so forth.

12 Bergson, Time and Free Will, 172.

${ }^{13}$ See, in particular, Henri Bergson, Matter and Memory, trans. Nancy Paul and Scott Palmer (New York: Zone Books, 1991), 185-186; Creative Evolution, trans. Arthur Mitchell (New York: Dover, 1998), 6-7, 248; The Creative Mind, trans. Mabelle Andison (New York: Dover, 2007), 8.

14 Original text: “Je résume ce que je viens de dire : en somme, contingence et liberté, tout cela signifie création ; la liberté pour nous, c'est de la création. . . . Nous avons déjà fait cette comparaison, mais nous y reviendrons souvent ; la liberté 
est une création au sens où l'on prend ce mot quand on dit qu'il y a création dans une œuvre d'art. Qu'est-ce qu'on entend par là ? On n'entend pas par là que l'œuvre d'art soit une production ex nihilo, qu'elle soit faite de rien; on entend par là qu'étant donné les conditions qui ont concouru à la production de l'œuvre, l'œuvre, si c'est véritablement l'œuvre d'un artiste, ajoute à ces conditions quelque chose d'absolument nouveau, d'absolument imprévisible." Bergson, L'évolution $d u$ problème de la liberté, 118.

15 Bergson, Time and Free Will, 221. See also: 142, 217.

${ }^{16}$ Bergson, Time and Free Will, 169-170.

${ }^{17}$ Bergson, Time and Free Will, 211-212.

18 Bergson, Time and Free Will, 146-148.

${ }^{19}$ Bergson, Time and Free Will, 150-152.

20 Bergson, Time and Free Will, 152-153.

21 Bergson, Time and Free Will, 154-155.

22 Bergson, Matter and Memory, 11-14.

23 Bergson, Creative Evolution, 114-115; Mind-Energy, trans. Wildon Carr (London: Greenwood Press, 1920), 43-45.

${ }^{24}$ Bergson, Time and Free Will, 199-200.

${ }^{25}$ Bergson, Time and Free Will, 170.

${ }^{26}$ In more contemporary terms, we can point out that our episodic memories (which relate to episodes of our life) are singular, and that our semantic memories (which correspond to general representations) also have something singular because they are formed from our episodic memories. Our semantic memories are personal generalities, so to speak.

27 Bergson, Time and Free Will, 158-160.

28 Bergson, Time and Free Will, 164.

${ }^{29}$ Bergson, Time and Free Will, 174.

30 Bergson, Time and Free Will, 174.

31 Bergson, Time and Free Will, 175.

32 Bergson, Time and Free Will, 176-177.

${ }^{33}$ Bergson uses a quote from Stuart Mill who himself criticizes classical indeterminism. See Time and Free Will, 173-174. In the book cited by Bergson, Mill criticizes four philosophers: Patrick P. Alexander, Henry L. Mansel, Thomas Reid, and Immanuel Kant. See John Stuart Mill, An Examination of Sir William Hamilton's Philosophy (London: Routledge, 1979), 449-469. 
34 René Descartes, The Philosophical Writings of Descartes, vol. 2 (Cambridge: Cambridge University Press, 1984), 40; vol. 3 (Cambridge: Cambridge University Press, 1991), 244-245.

35 Bergson, L'évolution du problème de la liberté, 215.

36 Immanuel Kant, Critique of Practical Reason, in The Cambridge Edition of the Works of Immanuel Kant. Practical philosophy, trans. Mary Gregor (Cambridge: Cambridge University Press, 1996), 218.

${ }^{37}$ According to Bergson, there is a certain continuity between Descartes and Kant on freedom, Kant only pushing the logic of Descartes further by clearly affirming the intelligibility of freedom. For more details on this continuity, see Bergson, L'évolution du problème de la liberté, 311-327.

38 See, in particular, Timothy O'Connor, Persons and Causes (New York: Oxford University Press, 2000), 24; Randolph Clarke, Libertarian Accounts of Free Will (Oxford: Oxford University Press, 2003), 3; Roderick Chisholm, "Human Freedom and the Self," in Free Will, 2nd ed., ed. Gary Watson (New York: Oxford University Press, 2003), 26-37; Robert Kane, A Contemporary Introduction to Free Will (New York: Oxford University Press, 2005), 6-7; Peter van Inwagen, Metaphysics, 4th ed. (Boulder: Westview Press, 2014), 267. For the diagram of alternative possibilities, see Kane and van Inwagen.

${ }^{39}$ See: O'Connor, Persons and Causes, 90-91; Clarke, Libertarian Accounts, 94; Kane, A Contemporary Introduction, 144-145.

40 See: Carl Ginet, On Action (Cambridge: Cambridge University Press, 1990), 149;

O'Connor, Persons and Causes, 89; Clarke, Libertarians Accounts, 46, 94-95.

41 Bergson, Time and Free Will, 176-78.

42 Ibid.

43 Bergson, Time and Free Will, 174.

${ }^{44}$ Bergson, Time and Free Will, 175-176.

45 Bergson, Time and Free Will, 175-176, 211.

${ }^{46}$ In Time and Free Will, Bergson speaks of the "common sense" (176). However, if we take into account the analyses of Creative Evolution and The Creative Mind, it is clear that we can speak here of intelligence.

${ }^{47}$ Bergson, Time and Free Will, 175-177.

48 Bergson, Time and Free Will, 180-181.

49 Ibid.

${ }^{50}$ Bergson, Time and Free Will, 175, 183.

${ }^{51}$ Bergson, Creative Evolution, 3-4.

52 Bergson, Time and Free Will, 178-180. 
53 Bergson, Time and Free Will, 179.

${ }^{54}$ Bergson, The Creative Mind, 8.

${ }^{55}$ Bergson, Time and Free Will, 177-178.

${ }^{56}$ Bergson, Time and Free Will, 166.

${ }^{57}$ Bergson, Time and Free Will, 167.

${ }^{58}$ Bergson, Time and Free Will, 172.

${ }^{59}$ Bergson, Time and Free Will, 165.

60 Bergson, Time and Free Will, 170.

${ }^{61}$ Bergson, Time and Free Will, 165.

${ }^{62}$ Bergson, Time and Free Will, 170.

${ }^{63}$ Several contemporary philosophers make a similar analysis. See, in particular, Timothy O'Connor, “Conscious Willing and the Emerging Sciences of Brain and Behavior," in Downward Causation and the Neurobiology of Free Will, ed. George Ellis, Nancey Murphy, and Timothy O'Connor (New York: Springer, 2009), 173-186; Eddy Nahmias, "Scientific Challenges to Free Will," in A Companion to the Philosophy of Action, ed. Constantine Sandis and Timothy O'Connor (Malden: Wiley-Blackwell, 2010), 345-356; Alfred Mele, Free: Why Science hasn't Disproved Free Will (Oxford: Oxford University Press, 2014), 13-16.

64 Bergson, Time and Free Will, 166.

${ }^{65}$ Bergson, Time and Free Will, 167-168.

${ }^{66}$ Bergson, Time and Free Will, 166.

${ }^{67}$ Bergson, Time and Free Will, 170.

68 Bergson, Time and Free Will, 166.

${ }^{69}$ Bergson, Time and Free Will, 167.

70 Bergson, Time and Free Will, 172.

71 Bergson, Time and Free Will, 219-220, 230.

72 Bergson, Time and Free Will, 219.

${ }^{73}$ For this point, see, in particular, Bergson, The Creative Mind, 135, 155.

${ }^{74}$ Bergson, Time and Free Will, 167.

${ }^{75}$ Bergson, Time and Free Will, 172.

${ }^{76}$ Bergson, Time and Free Will, 220-221.

77 Bergson, The Creative Mind, 23-24.

${ }^{78}$ See, in particular, Peter van Inwagen, “Free Will Remains a Mystery," Philosophical Perspectives 14 (2000), 1-19; Alfred Mele, Free Will and Luck (Oxford: Oxford University Press, 2006), ch. 3.

${ }^{79}$ Bergson, Time and Free Will, 157.

80 Bergson, Time and Free Will, 158. 
${ }^{81}$ See, in particular, William Barnard, Living Consciousness: The Metaphysical Vision of Henri Bergson. (Albany: State University of New York Press, 2011), ch. 7; Mark Sinclair, Bergson, 74.

82 See, in particular, Ran Lahav, "Between Pre-determination and Arbitrariness : a Bergsonian Approach to Free Will," Southern Journal of Philosophy 29, no. 4 (1991), 487-499. Mark Robson, "Is Ultimate Moral Responsibility Metaphysically Impossible ? A Bergsonian Critique of Galen Strawson's Argument," Philosophy 92, no. 4 (2017), 519538. Lahav and Robson seek to show that, for Bergson, the free act emanates from an imperfectly determined self. In reality, as I tried to explain in part 2 of the article, for Bergson, the free act emanates from a self whose quality is perfectly determined, but singular.

83 Several commentators have noticed this : Vladimir Jankélévitch, Henri Bergson (Paris : Presses Universitaires de France, 1959), 66-68; Alan Lacey, Bergson ( London: Routledge, 1989), 54-56; Frédéric Worms, Bergson ou les deux sens de la vie (Paris: Presses Universitaires de France, 2004), 76, 83-85, Suzanne Guerlac, Thinking in Time: An Introduction to Henri Bergson (Ithaca: Cornell University Press, 2006), 79-

80.

${ }^{84}$ Bergson, Time and Free Will, 148.

85 Bergson, Time and Free Will, 174.

${ }^{86}$ Bergson, Time and Free Will, 199-221.

${ }^{87}$ Bergson, Time and Free Will, 204-207.

88 Bergson, Time and Free Will, 211-212.

89 Ibid.

90 Bergson, Mind-Energy, 230.

91 Bergson, Time and Free Will, 216-217.

92 Bergson, Creative Evolution, 210-216.

93 Bergson, Time and Free Will, 208-209.

${ }^{94}$ Henri Bergson, The Two Sources of Morality and Religion, trans. Ashley Audra and Cloudesley Brereton (Notre Dame, Indiana: University of Notre Dame Press, 1977), 12.

95 Bergson, Creative Evolution, 314-345.

96 See above.

97 Bergson, Time and Free Will, 159-160.

98 Bergson, Time and Free Will, 170.

${ }^{99}$ Bergson, Matter and Memory, 186. See also Bergson, Creative Evolution, 7.

100 Bergson, Time and Free Will, 170.

101 Bergson, Time and Free Will, 157.

102 Bergson, Time and Free Will, 158. 
103 Ibid.

104 In contemporary literature on free will, moral responsibiliy is viewed more as an agent's moral quality than as a moral duty. See, in particular, John Fischer, Robert Kane, Derk Pereboom, and Manuel Vargas, Four Views on Free Will (Malden: Blackwell Publishing, 2007), 1-2. However, in the strict sense of the term, moral responsibility is the moral duty to account to someone for one's actions.

105 Bergson, Time and Free Will, 166-167.

106 Bergson, The Two Sources, 34-35. 